\title{
Entrenamiento, capacitación y financiamiento con crecimiento sostenido en las pequeñas empresas del sector industrial en San Luis Potosí
}

\author{
Mario Alberto Martínez Rojas ${ }^{1}$ \\ Universidad Autónoma de San Luis Potosí \\ amtz75@gmail.com \\ Gloria Cristina Palos Cerda² \\ Universidad Politécnica de San Luis Potosí \\ cristina.palos@upslp.edu.mx \\ José G. Vargas-Hernández ${ }^{3}$ \\ Universidad de Guadalajara \\ josevargas@cucea.udg.mx
}

Fecha de recepción: 10 de febrero de 2017

Fecha de aprobación: 10 de mayo de 2017

DOI: https://doi.org/10.21158/01208160.n82.2017.1650

Cómo citar este artículo/ To reference this article/ Comment citer cet article/ Para citar este artigo:

Martínez, M. A.; Palos, G. C. y Vargas-Hernández, J. G. (2017). Entrenamiento, capacitación y financiamiento con creci-miento sostenido en las pequeñas empresas del sector industrial en San Luis Potosí.

Revista EAN, 82, pp. 91-118. https://doi.org/10.21158/01208160.n82.2017.1650

\section{Resumen}

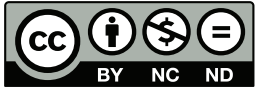

El objetivo de la presente investigación fue determinar la relación existente entre el nivel de financiamiento, la capacitación, el entrenamiento por parte del empresario y el crecimiento sostenido de las pequeñas empresas industriales en San Luis Potosí (México). En lo que respecta a la metodología, se identificaron como variables independientes la capacitación, el entrenamiento y el financiamiento y con el fin de identificar las relaciones complejas y multidimencionales, se propone el análisis de correlación que conjuntamente determine la intensidad de la correspondencia entre dos o más de estas variables independientes con la dependiente (crecimiento). Así mismo, se realizó un análisis de regresión múltiple, cuyo propósito fue usar el valor de las variables independientes para predecir la única variable dependiente seleccionada. Lo concluido en esta investigación se configura solo como una tendencia hacia la realidad del comportamiento de las empresas que componen el universo de las pequeñas empresas del sector industrial de la población objeto del estudio.

\section{Palabras clave}

Entrenamiento, capacitación, financiamiento, crecimiento, empresa.

1 Contador público. Maestro en Administración por la Universidad Autónoma de San Luis Potosí. Doctor en Administración por la Universidad Autónoma de Querétaro. Profesor e investigador en la Universidad Politécnica de San Luis Potosí.

2 Licenciada en Administración y Gestión por la Universidad Politécnica de San Luis Potosí. Magíster en Business Administration por la Andhra University, India. Profesora investigadora en la Universidad Politécnica de San Luis Potosí, México.

3 Contador público de la Universidad Politécnica de San Luis Potosí. Magíster en Business Administration en Administración Industrial (Pacific States University). Doctorado en Administración Pública por Columbia States University. Doctorado en Economía por Keele University, England. Profesor investigador de la Universidad de Guadalajara. ORCID: http://orcid.org/0000-0003-0938-4197 


\title{
Training and Financing for Sustainable Development of Small and Medium - size Companies from the Industrial Sector in San Luis Potosi
}

\begin{abstract}
This research paper aims at describing the existing relation between financing level, management training and sustainable growth of industrial small companies in San Luis Potosi, Mexico. In regard with the methodology used, independent variables such as training and financing were identified. Besides, aiming at stating multidimensional and complex relations, a correlation analysis was made to determine the correlation intensity between two or more independent and dependent variables (growth). Similarly, a multiple regression analysis was made to use the current value of independent variables to predict the unique selected dependent variables. Its resulting outcome turns to be a current trend to meet the real behavior of companies which make up the universe of small and medium- size companies of the studied industrial sector.
\end{abstract}

Key words. Training, financing, growth, small and medium- size companies.

\section{Entraînement, formation et financement des petites entreprises du secteur industriel de Sain Luis Potosí dans un contexte de croissance soutenue}

Resumé. L'objectif de cette recherche est de déterminer la relation existante entre le niveau de financement, la formation, les qualifications de l'entrepreneur et la croissance des petites entreprises industrielles de Sain Luis Potosí (Mexique). Pour ce qui est de la méthodologie, nous avons identifié les variables indépendantes de formation, d'entraînement et de financement afin d'identifier les relations complexes et multidimensionnelles. Nous proposons une analyse de corrélation qui détermine conjointement l'intensité de la correspondance entre deux ou plusieurs de ces variables indépendantes avec la variable de référence. Par ailleurs, nous avons effectué simultanément une analyse de régression multiple, dont l'objectif a été d'utiliser la valeur des variables indépendantes pour prédire les fluctuations de l'unique variable dépendante sélectionnée. La conclusion cette recherche est une tendance de la réalité du comportement des entreprises composant l'univers des petites entreprises du secteur industriel de la zone géographique objet d'étude.

Mots clefs. Entraînement, formation, financement, croissance, entreprise.

\section{Treinamento, capacitação e financiamento com crescimento sustentado nas pequenas empresas do setor industrial de San Luis Potosí}

\begin{abstract}
Resumo. O objetivo da presente pesquisa foi determinar a relação existente entre o nível de financiamento, a capacitação, o treinamento por parte do empresário e o crescimento sustentado das pequenas empresas industriais de San Luis Potosí (México). No relacionado à metodologia, identificaram-se como variáveis independentes a capacitação, o treinamento e o financiamento e, com o fim de identificar as relações complexas e multidimencionais, propõe-se a análise de correlação que conjuntamente determine a intensidade da correspondência entre duas ou mais destas variáveis independentes com a dependente (crescimento). Por outro lado, realizou-se uma análise de regressão múltipla, cujo propósito foi usar o valor das variáveis independentes para predizer a única variável dependente selecionada. $A$ conclusão configura-se como uma tendência para a realidade do comportamento das empresas que compõem o universo das pequenas empresas do setor industrial da população objeto de estudo.
\end{abstract}

Palabras chave. Treinamento, capacitação, financiamento, crescimento, empresa. 


\section{Introducción}

a pequeña empresa a menudo se asocia con una doble función para la familia como propietaria y directiva de la empresa (Dyer y Dyer, 1986). En términos económicos, las familias hacen inversiones específicas de la empresa en capital humano, lo cual las hace difíciles a renunciar al control (Thomsen y Pedersen, 2000).

Un obstáculo para el crecimiento de las empresas es no poder resolver los problemas a los que están expuestas. Las causas de la falta de liquidez en las pequeñas empresas son diversas, como ineficiencias productivas, políticas de capital de trabajo incorrectas, una ausencia del control de gastos, y hasta por la falta de calidad de sus productos. También tienden a carecer de suficiente infraestructura física, personal especializado, documentación en orden, así como información de mercado y hasta de sus propios estados financieros que dificultan la elaboración eficiente de un estudio de crédito que permita determinar adecuadamente los términos del financiamiento que se requiere resolver.

La existencia en la empresa de propietarios con un parentesco familiar, y que esto a su vez tenga incidencia en la toma de decisiones empresariales, puede dar lugar a determinadas perturbaciones en ella. El hecho de que la propiedad se encuentre en manos de una familia puede dar lugar a conflictos de poder especialmente graves $y$, sobre todo a problemas en cuanto a la dimensión de la empresa, debido a las limitaciones que supone la autofinanciación. Así, dado que una parte importante de la riqueza de estas familias propietarias suele estar invertida en estas empresas y que las familias a menudo no quieren arriesgarse a perder el control permitiendo la entrada de extraños, las empresas de propiedad familiar pueden ser relativamente adversas al riesgo y es más probable que tengan restricciones de capital que otras (Thomsen y Pedersen, 2000).

Es, precisamente, esta clase de distorsiones las que llevaron a algunos de los primeros autores a investigar en este campo. Hollander y Elman (1988) lo denominan el enfoque racional en el tratamiento de la empresa familiar. Se plantea que en este tipo de empresa existen dos organizaciones paralelas: la familia representa el componente no racional y la empresa representa el componente racional. Cuando ambos componentes se enfrentan, es muy probable que la racionalidad empresarial se vea limitada por la confusión de los intereses familiares con los de la empresa, de manera que en muchas ocasiones las decisiones de los propietarios se guíen más por los sentimientos que por la propia lógica.

De ahí que la solución propuesta sea la de suprimir las influencias familiares en la empresa por medio de la introducción de directivos profesionales ajenos a la familia o privando los intereses de la empresa sobre los de la familia (Danco, 1992). Los autores que aplican este planteamiento racional no admiten la posibilidad que la presencia de familiar pueda aportar alguna ventaja a las empresas. De hecho, gran parte de la literatura existente sugiere que es posible que se produzca una subordinación de los objetivos empresariales a los objetivos familiares o al menos que se desarrollen mecanismos para acomodar estos dos sistemas a menudo enfrentados entre sí. La implicación es que las empresas familiares son menos "profesionales" que otras configuraciones de propiedad alternativas (Rubio y Aragón, 2009). 
Por su parte, el papel que desempeña el Gobierno es determinante para las pequeñas empresas por lo que se crean diversos fondos para apoyarlas según los objetivos que les atañen. Para poder entender la situación económica en la que se encuentra la pequeña empresa en el país y las posibilidades de desarrollo que ella misma tiene es necesario analizar una compleja serie de factores que comprenden desde las experiencias exitosas de desarrollo que se han dado y están dando en el mundo de los negocios hasta detectar las causas que determinan que la pequeña empresa pueda tener una alta productividad, desarrollo o crecimiento, y una mejor integración con el medio social y con los objetivos institucionales del Gobierno para generar apoyo a estas empresas.

Esta investigación aporta un mayor conocimiento de la situación que se vive en las pequeñas empresas industriales que se encuentran localizadas en San Luis Potosí con relación a las variables estudiadas -entrenamiento, capacitación, financiamiento y el crecimiento sostenido de la empresa-. Su objetivo fue determinar la relación que existe entre el nivel de financiamiento, capacitación y entrenamiento por parte del empresario, y el crecimiento sostenido de las pequeñas empresas industriales en San Luis Potosí.

La pregunta central de investigación fue esta: ¿cuál es la relación del entrenamiento, la capacitación y el financiamiento con el crecimiento sostenido para las pequeñas empresas industriales en San Luis Potosí? Consecuentemente, la hipótesis giro en torno a la afirmación que existe una relación directa entre la capacitación, el entrenamiento y el nivel de financiamiento como factores que influyen en el crecimiento sostenido de las pequeñas empresas industriales en San Luis Potosí.
Respecto de la metodología utilizada, se identificaron las variables independientes de capacitación, entrenamiento y financiamiento para conocer sí es la mejor clasificación que nos permita optimizar los recursos. A fin de identificar las relaciones complejas y multidimencionales se propone el análisis de correlación que conjuntamente determine la intensidad de la correlación entre dos o más variables independientes con la dependiente -crecimiento-. Después de encontrar la mejor clasificación y distribución de las variables independientes, se procedió a hacer un análisis de regresión múltiple cuyo objeto fue usar el valor de las variables independientes para predecir la única variable dependiente seleccionada.

Los resultados obtenidos muestran que para el planteamiento de la primera hipótesis en el grupo de empresas industriales estudiadas sí existe una relación directa entre la variable de entrenamiento y la variable de crecimiento. En el caso de la segunda hipótesis sí existe una relación directa entre la variable de capacitación y la variable de crecimiento en las empresas estudiadas, caso contrario para la tercera hipótesis donde se afirma que no existe una relación directa entre la variable de financiamiento y la variable de crecimiento en las empresas estudiadas. Para la cuarta hipótesis se evidenció que los empresarios sí cuentan con la información necesaria para poder llegar a tener un financiamiento para su empresa. $Y$ finalmente, para la quinta hipótesis, las variables determinantes para generar un crecimiento sostenido son la capacitación y el entrenamiento.

Lo concluido en esta investigación es solo una tendencia hacia la realidad del comportamiento de las empresas que conforman el universo de las pequeñas empresas del sector industrial por la forma en que fueron seleccionadas las empresas de la muestra. 


\section{Marco teórico}

\subsection{Entrenamiento y capacita- ción en las pequeñas empresas}

Las pequeñas empresas tienen su vida propia a partir de la integración de los individuos que la componen y su relación con el exterior. Esa personalidad es única y está íntimamente relacionada con la de su dueño o director quien no puede solo llevar a cabo la estrategia debido a que requiere el apoyo, los conocimientos y la energía de un grupo de personas

p.223 que lo acompañe, con valores compartidos
y con ideales comunes más allá de las diferencias que inevitablemente existan.

El éxito radica en la utilización de las experiencias recopiladas durante años por parte de los directivos de la empresa y observando en los trabajadores el tipo de liderazgo que ejercen dentro de ella (National Research Council, 2000). El contexto en el que se desarrolla la pequeña empresa está en constante cambio, las decisiones que toman empresarios y directivos requieren nuevas bases de conocimiento para comprender los procesos de adaptación de sus estrategias exitosas y respectivos requerimientos (Arechavala y Madriga, 2000). El éxito dentro de las pequeñas empresas no se expresa exclusivamente en términos económicos de costos y precios relativos. Por el contrario, se amplía para incorporar otros atributos de la calidad o los servicios posventa determinantes de la diferenciación en un contexto de mercado de competencia imperfecta (Raymond, Maroto y Melle, 1999).
Por tanto, se admite que un nuevo estilo de administración es requerido para las pequeñas y medianas empresas (Serra, Iriarte y Le Fosse, 2000). Este debe comprender la forma en que se están desarrollando los mercados de enfoque a largo plazo y que sea capaz de elaborar rápidos y complejos movimientos para evolucionar y liderar. Las pymes deben ser capaces de acompañar el ritmo del cambio como elemento intrínseco de la naturaleza como lo es también en el mundo de los negocios.

Las empresas de ayer no son las mismas de hoy. Actualmente, el mundo se encuentra compuesto de una sociedad de organizaciones donde todas ellas requieren ser administradas de forma eficiente y rentable, siguiendo una visión y una misión bien definidas y trazadas de acuerdo con un plan estratégico. El éxito en el mercado de las pequeñas empresas gira en un claro entendimiento de aquellas necesidades y preocupaciones y de la habilidad de motivar a los realizadores de decisiones a tomar acción.

El enfoque al proceso know how el dominio del saber cómo -no del saber qué-, se ve reflejado también en la economía donde impera el conocimiento y el reino de la información sobre los capitales de recursos que han revolucionado la impor-tancia del producto, para centrarla en el imperio del conocimiento -capital intelectual- en medio de un ambiente de globalización, comunicación, tecnología e información que pasa al producto a un nivel dependiente del conocimiento. 


\subsection{Caracterización del administrador y del gerente de las pequeñas empresas}

El término directivos lo utilizamos para referirnos al mando superior dentro de una pequeña empresa, aunque también puede utilizarse para mandos inmediatos al superior, o de nivel lateral, cuando se usa en plural. En todos los casos nos referimos a la función de administrar en sus niveles de mando superior o de alta dirección el nivel máximo de autoridad, a excepción cualquier otro nivel de mando dependiente dentro de la pyme.

De hecho, el administrador debiera ser líder y en algunos casos debe desempeñar ambas funciones cuando hay una sola persona al frente de la empresa. El líder debe conocer lo que sucede en la administración para poder dirigirla refiriéndose primariamente a la gestión de la parte directiva analizando el desempeño de la función administrativa, extensión y responsabilidad de la propia función directiva.

La mayor parte de perjuicios que recibe las empresas son debido a las deficiencias en la administración directiva y se deben en gran parte a la falta de competencia profesional también conocida como habilidad administrativa, consciente o inconsciente, responsable $\mathrm{o}$ no, en los directivos de las empresas. Estas deficiencias se deben a la falta de conocimiento y de las habilidades para aplicarlas. Dotlich y Cairo (2003) citan como causas de fracaso de los directores las conductas y las características de cómo son los directivos. Desde otros puntos de vista complementarios, podríamos considerar los siguientes enfoques, para comprender mejor las fallas (Figura 1).

Figura 1. Enfoque de los directivos.

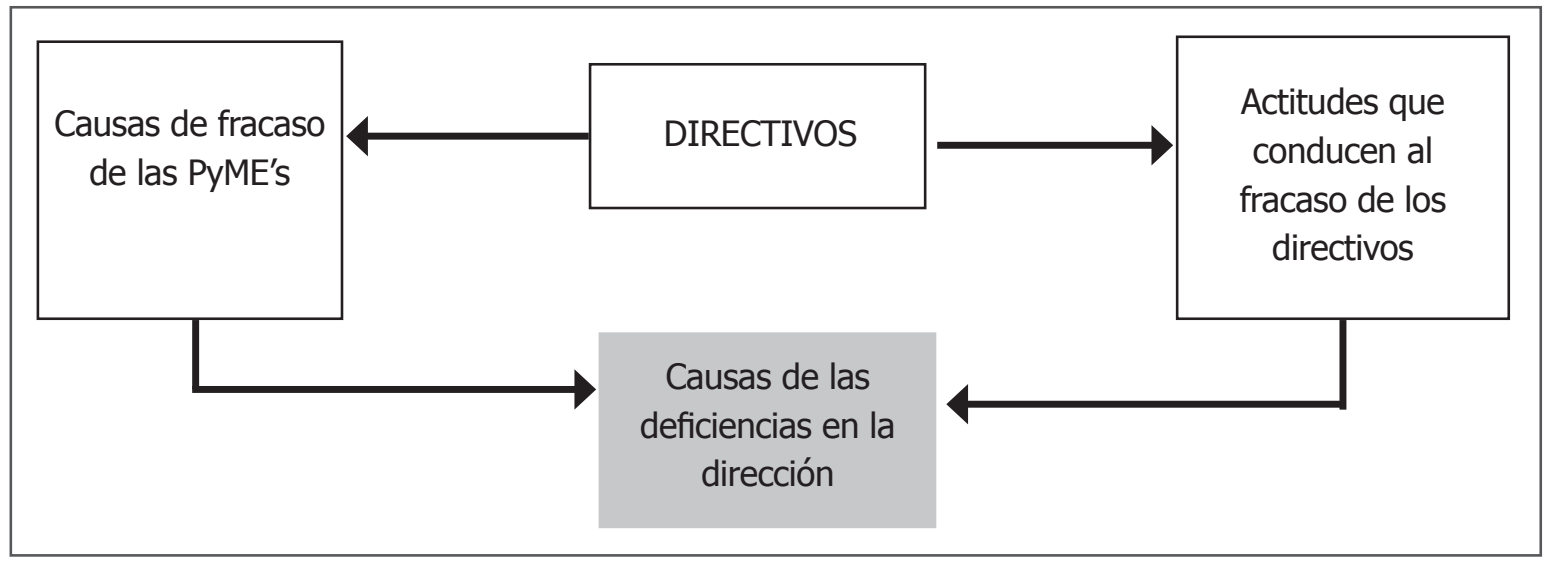

Fuente. Estrada, (2015).

El líder, en la concepción actual de su nivel dentro de la organización, realmente desempeña estos dos papeles (Figura 2). 
Figura 2. Enfoque del directivo y de la dirección.



Fuente. Estrada, (2015).

Administración y logro de objetivos son sinónimos. Decir administración implica logro de objetivos y en estos términos la frase administración por objetivos resulta pleonástico (Estrada, 2015). Los objetivos son la razón de ser de las organizaciones y de la administración donde la relación de esta última con las organizaciones y en este caso con las PyMEs debe ser la misma. Por esa razón, se afirma que el destino de las PyMEs está ligado y es dependiente de la administración. Por lo anterior, se plantea en este estudio las causas de fracaso de las PyMEs dependiendo en su mayor parte de quienes las dirigen, en la forma como lo define Covey (1997):

- Aspectos positivos: cuáles son los requerimientos para un buen desempeño directivo, en un líder o administrador, así como las causas que se debe el éxito a su desempeño.

- Anatomía del desempeño: la anatomía del desempeño que dan como resultado la adopción de hábitos.

Visto desde un enfoque administrativo, se describe las funciones de un directivo (Figura 3):

Figura 3. Caracterización de los administradores en función de los niveles jerárquicos.

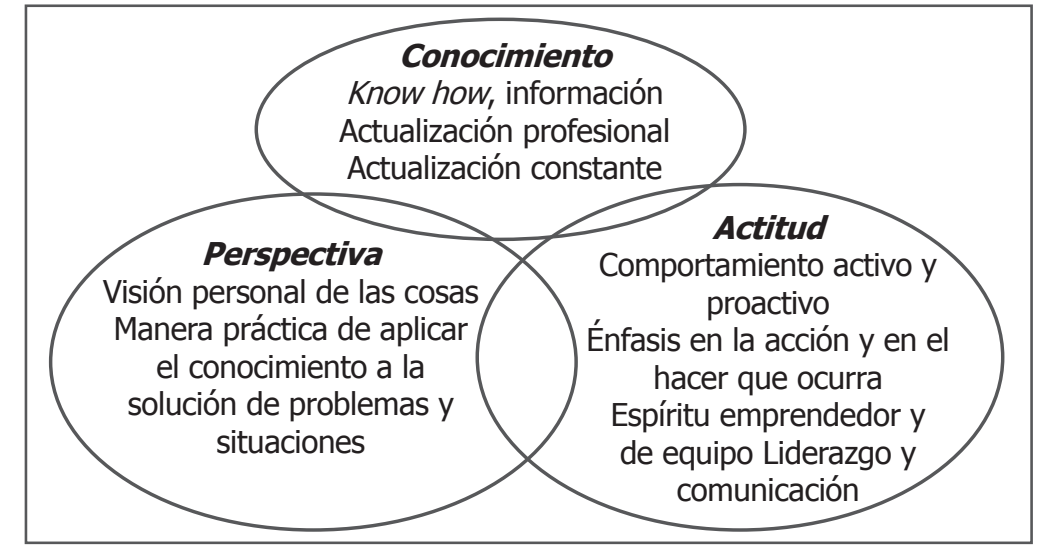

Fuente. Covey, (1997). 
Es el administrador o gerente la figura de sumo valor, el eje principal, el líder, el guía y promotor de que todos sigan la ruta correcta. En los últimos años se ha podido observar una transformación en el modo de operar de las empresas, debido principalmente a la tecnología. Al cambiar las empresas, de igual forma se ha exigido un cambio en las personas que las dirigen y un cambio en todo el personal que trabaja en ellas. Ahora, no importa el departamento que se administre, el gerente debe tener un conocimiento integral para poder entender el engranaje empresarial y establecer metas y planes que se integren con el resto de la empresa.

\subsection{El concepto de entrenamiento en las organizaciones modernas}

El conocimiento no es algo estático, sino que debe darse con dinamismo a las empresas a fin de que sean competitivas y estén preparadas para los retos futuros a los que se puedan enfrentar como organización. Para ello, la transmisión de la información a nuestros recursos humanos será mediante diferentes mecanismos que nos serán de gran ayuda para cumplir con las necesidades de la empresa.

Capacitar es desarrollar las destrezas y habilidades intelectuales de alguien para hacerlo competente en una determinada tarea. A lo cual podemos agregar que quien capacita posee las habilidades por compartir y es responsable de los resultados de este proceso de inversión en la organización. La capacitación es un proceso largo y es resultado de años de aprendizaje cuando se dan pequeños pasos a corto plazo con objetivos específicos. El aprendizaje es posible verlo en dos sentidos: es una función bilateral y continúa, no tiene barrera o elección entre lo empírico y lo analítico. Para que la capacitación sea posible se necesita la obtención de conocimientos que se da con el aprendizaje de las personas a las que se está preparando.

Sin embargo, todo conocimiento requiere entrenamiento, el cual está constituido por un hábito rutinario que desemboca en el desarrollo de todas las habilidades que posee un directivo. Entrenar conjunta un esfuerzo continuo que es apoyado por los diferentes miembros de un equipo que pueden observar las distintas habilidades de los compañeros y ayudar a facultar a los demás. Entrenar es dar las herramientas necesarias para el desempeño de las actividades designadas.

En la literatura existen dos enfoques, uno es el desarrollado por consultores empresariales, y el desarrollado por académicos, aunque los dos comparten la idea principal sobre la importancia del entrenamiento en la innovación y generación de capacidades tecnológicas para la competencia globalizada. Las diferencias se encuentran en el nivel de reflexión sobre la apropiabilidad, acumulación y naturaleza del conocimiento (Hernández y Sánchez, 2004) y el papel de los actores organizacionales en el juego de la cooperación (Crozier y Friedberg, 1999; Savall, 2003). Como lo señala Dutrénit y VeraCruz (2002), las empresas compiten sobre la base de capacidades y competencias distintivas que se acumulan a lo largo del tiempo.

El entrenamiento está siendo profundamente abordado e implementado por distintos sectores académicos y productivos, el cual impregna su trascendencia de especial forma si lo comparamos con las técnicas clásicas de diagnóstico de producto-mercado 
llamado efecto de experiencia y otras bases (Gélinier, 1989). Se puede constatar cómo un proceso que necesitaba, tiempo atrás, años para generar reducciones en los costos de producción, hoy en día, necesita solo meses si se trabaja adecuadamente la gestión del entrenamiento. De tal modo que el efecto de la experiencia se convertía, fruto del proceso descrito, tanto en fuente de ventaja competitiva como de estrategia de sostenibilidad en el ciclo del producto.

La ciencia ha ido progresando y en consecuencia diversas disciplinas estudian el entrenamiento como un tema incipiente del management contemporáneo. Sin embargo, un concepto tan abierto ha dado pie a interpretaciones variadas que difundían su significado en función de la teoría, el autor o la empresa que lo ponga en práctica. Por tanto, se habrá de considerar las partes integradoras de las técnicas del entrenamiento que involucra la comunicación interna y externa de la empresa, su cultura organizativa, los conocimientos organizacionales y por supuesto su capital.

La cultura organizativa es crítica para el éxito y la vitalidad de este tipo de proyectos por lo que, al mismo tiempo, también es fundamental conocer los parámetros que la constituyen y determinan para contribuir a las modificaciones que permitan alcanzar funcionamientos más dinámicos. Las nuevas propuestas organizacionales se basan en modelos colaborativos, inter e intra organizacionales (Arvanitis, 1996) dirigidos a crear las condiciones necesarias para la apropiación del conocimiento, la innovación y la creación de potencial que permitan a las organizaciones alcanzar niveles de productividad requeridos ante la competencia globalizada con el entrenamiento. Cuando hablamos de creación de potencial e innovación nos referimos automáticamente al capital intelectual 0 inmaterial de la organización centrado en el conocimiento que tienen los actores que interactúan en el entorno y que ponen a su disposición para incrementar sus resultados económicos y sociales.

Las pequeñas y medianas empresas que pretenden su permanencia y desarrollo en un mercado globalizado deben lograr la armonización de todos los recursos de que disponen. Siendo el capital intelectual el más importante de los recursos al tener la capacidad de crear valor y la capacidad de decidir cómo jugar el juego de la cooperación o resistencia en la organización (Crozier y Friedberg, 1990).

Entonces, un reto para la organización es la generación de mecanismos que conduzcan al entrenamiento óptimo de sus individuos para que se unan a los intereses de la organización y cooperen con la socialización de aprendizajes y conocimientos. Las técnicas de entrenamiento para la capacitación se refieren estrictamente a una gestión basada en la cooperación y la confianza de todos los actores organizacionales, internos y externos, que comparten una misión y visión organizacional y los resultados económicos y sociales de esta. A su vez se refieren a las organizaciones que promueven el aprendizaje colectivo basado en la interacción social con diferentes actores siendo el proceso interacción lo que va a permitir el tránsito del conocimiento tácito al explícito (Nonaka, Takeuchi y Kocka, 1999). 


\section{Gestión financiera en las PyMEs}

- n el caso de las PyMEs, la mayoría carece de un planeamiento estratégico sostenido donde el involucramiento del empresario sea contundente y de estrecha vinculación con la cultura organizacional. La orientación estratégica debe contar con una visión de oportunidad para la identificación de oportunidades de negocios, agudeza perceptiva para captar los cambios que se generan en los negocios, capacidad y manejo de información estratégica y capacidad de autodiagnóstico para detectar las habilidades competitivas.

En el actual e irreversible contexto global de la economía e internacionalización de los mercados, las empresas están afrontando un fenómeno creciente de intensificación de la competencia. Los productos y los servicios compiten en un único mercado mundial y las

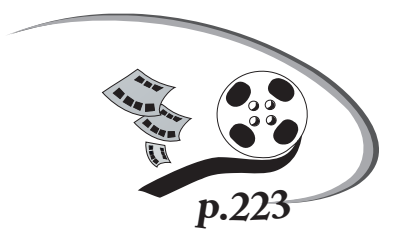

empresas tienen que ir desarrollando permanentemente sus ventajas competitivas. Entre estos grandes retos, está presente la mejora de la estructura y gestión financiera de las empresas, pues ambas constituyen un factor básico condicionante de su competitividad y eficacia interna. Las PyMEs tienen necesariamente que profesionalizar su gestión financiera. En estas empresas, a pesar de la diversidad de instrumentos financieros disponibles, muchos de ellos son desconocidos y las dificultades reales de acceso a la financiación son un hecho constatado, así como las carencias existentes sobre información, formación y gestión financiera.

Existen características diferenciadoras de la estructura financiera de las pymes en relación con empresas de mayor tamaño, como son las dificultades al acceso de financiación ajena, mayor dependencia bancaria, concentración del pasivo bancario a corto plazo y mayor costo financiero de los recursos ajenos. Los directivos de las pymes deben tener un dominio global de la gestión financiera haciendo uso de una cultura informática para un manejo óptimo de los conceptos contables, financieros y fiscales en su organización.

\subsection{Financiamiento para las PyMEs en México}

Como resultado de la dinámica de la economía en el ámbito internacional, nuestro país se encuentra inmerso en un proceso de transformación que persigue un mayor nivel de bienestar social que se ve reflejado en un crecimiento económico que impulsa la integración de las actividades industriales, comerciales y financieras. Entre las acciones emprendidas por el Gobierno federal en este sentido, se han implementado dos programas en los cuales participan instituciones y organismos públicos y privados. Los programas son el Plan Nacional de Desarrollo, el Programa Nacional de Financiamiento del Desarrollo y en los últimos años el Instituto del Emprendedor. Los tres casos involucran instituciones y organismos públicos y privados, con el objeto de generar las condiciones que impulsen un desarrollo sustentable en el ámbito empresarial.

Dentro de este proceso de transformación y de acuerdo con los objetivos del Plan Nacional de Desarrollo, el Gobierno federal, a través de las instituciones de fomento, otorga apoyos a las pymes; por ejemplo, asesoría 
y asistencia de la Secretaría de Economía. Para la pyme obtener financiamiento no ha sido una labor fácil. Si bien se ha publicado en diversos medios que ha aumentado el otorgamiento de créditos en nuestro país este incremento se refiere al denominado crédito al consumo, como los recursos para el capital de trabajo, el financiamiento de las ventas a crédito, ampliar, renovar o darle mantenimiento a la maquinaria.

El Fondo de Apoyo para la Micro, Pequeña y Mediana Empresa es un instrumento que busca apoyar a las empresas, en particular a las de menor tamaño y a los emprendedores, con el propósito de promover el desarrollo económico nacional, con el otorgamiento de apoyos de carácter temporal a programas y proyectos que fomenten la creación, el desarrollo, la consolidación, la viabilidad, la productividad, la competitividad y la sustentabilidad de las micro, pequeñas y medianas empresas. Lo anterior se basa en el acuerdo en el que se establecen las reglas de operación para el otorgamiento de apoyos del fondo PyME:
- Formación de emprendedores y creación de empresas.

- Innovación tecnológica.

- Gestión empresarial.

- Fortalecimiento empresarial.

- Proyectos productivos.

- Realización de eventos pyme y otras actividades e instrumentos de promoción.

- Programas de créditos disponibles para pequeñas empresas ubicadas en San Luis Potosí.

- Fondo de Fomento a la Integración de Cadenas Productivas.

- Fondo de Apoyo para la Micro, Pequeña y Mediana Empresa.

- Fondo de Apoyo para el Acceso al Financiamiento de las Micro, Pequeñas y Medianas Empresas.

- Programa de centros de distribución en los Estados Unidos.

- Apoyos para actividades de soporte para las pequeñas empresas.

\section{El desarrollo sustentable de las PyMEs}

Existen varios ejemplos que ilustran la Epreocupación por la sustentabilidad del desarrollo como la evaluación de los impactos que provocan estilos de desarrollo en el bienestar de las generaciones futuras. El enfoque de sustentabilidad se hace más complejo, ya que se suman criterios de trabajo que inciden en el manejo y uso de los recursos como participación ciudadana, políticas y de instituciones en el que ciertos proyectos de inversión tienden a desaparecer antes de que termine su vida útil. La sustentabilidad se analiza en lo macro, ya que depende de factores sectoriales y macroeconómicos, por eso, la carga de deuda externa contribuye a que sea menor el apoyo a los programas ambientales de largo plazo en razón de la escasez de recursos fiscales y requiere un equilibrio dinámico entre todas las formas de capital o acervos que participan en el


esfuerzo del desarrollo económico y social de los países, para que la tasa de uso del capital no exceda su propia tasa de reproducción.

En México se encuentra una transformación productiva que aumenta la participación 
de la sociedad a través de un ambiente más democrático que busca mejorar las condiciones de vida. El impacto de las políticas económicas causa efectos primarios y secundarios sobre el medio ambiente de las organizaciones, como los cambios en las tasas de interés - periodo de maduración de inversiones-, la reasignación del presupuesto fiscal -estructura de incentivos- 0 las devaluaciones de la moneda -tasa de extracción de los recursos naturales no renovables-. La revisión de programas sobre las políticas permitirá el equilibrio entre todas las formas de capital. La relación entre las políticas económicas y el medio ambiente de las organizaciones se manifiesta a través de:

- La disponibilidad y los beneficios del recurso, la distribución de actividades económicas y sociales, la asignación y uso de recursos, las ventajas del comercio internacional, la redistribución del problema ambiental, la eficacia de instrumentos económicos, la disponibilidad de recursos internos, los incentivos para invertir y reinvertir en un recurso.

- Las políticas macroeconómicas se evalúan por los impactos primarios o directos que a su vez provocan impactos indirectos.
- Las políticas económicas afectan el caudal de recursos y flujo explotable, debido a que modifican las ventajas comparativas de explotación.

Existen nuevas modalidades organizativas que apuntan hacia una mayor flexibilidad del proceso productivo y la disminución de sus costos, cuestión que se refleja en la calidad del producto. Este es el fundamento de la competitividad contemporánea.

Los conceptos de producción y demanda sincronizadas -just in time inventory-, producción sin defectos y control total de calidad -total quality control, entre otros, se refieren a este fenómeno. Su aplicación requiere estrechar vinculaciones entre proveedores, productores y usuarios, lo cual ha posibilitado los rápidos avances en el ámbito de las tecnologías de la información y de la comunicación. Por otro lado, los procesos de diseño, producción, distribución y comercialización permiten acortar los plazos de respuesta a las nuevas demandas del mercado e incentivar entre empresas de distintos países y sectores.

\section{Marco contextual}

\subsection{Estructura económica de las empresas en México}

Las micro, pequeñas y medianas empresas (MiPyMEs) tienen una gran importancia en la economía y el empleo en el ámbito nacional y regional. Las MiPyMEs representan alrededor del mundo el segmento de la economía que aporta el mayor número de unidades económicas y personal ocupado; de ahí la relevancia que reviste este tipo de empresas y la necesidad de fortalecer su desempeño.

Los criterios para clasificar a las mipymes son diferentes en cada país. De manera tradicional se ha utilizado el número de trabajadores como criterio para estratificar los establecimientos por tamaño y como criterios complementarios, el total de ventas anuales, los ingresos o los activos fijos. En el caso de México, a continuación se establece (Tabla 1) la estratificación de las MiPyMEs. 
Tabla 1. Estratificación empresarial en México.

\begin{tabular}{|l|l|l|l|c|}
\hline Tamaño & \multicolumn{1}{|c|}{ Sector } & $\begin{array}{c}\text { Rango de número } \\
\text { de trabajadores }\end{array}$ & $\begin{array}{c}\text { Rango de monto } \\
\text { de ventas anuales } \\
\text { (mdp) }\end{array}$ & $\begin{array}{c}\text { Tope máximo } \\
\text { combinado* }\end{array}$ \\
\hline Micro & Todas & Hasta 10 & Hasta MXN 4 & 4.6 \\
\hline \multirow{2}{*}{ Pequeña } & Comercio & Desde 11 hasta 30 & $\begin{array}{l}\text { Desde MXN 4.01 } \\
\text { hasta MXN 100 }\end{array}$ & 93 \\
\cline { 2 - 5 } & $\begin{array}{l}\text { Industria y } \\
\text { servicios }\end{array}$ & Desde 11 hasta 50 & $\begin{array}{l}\text { Desde MXN 4.01 } \\
\text { hasta MXN 100 }\end{array}$ & 95 \\
\hline \multirow{2}{*}{ Mediana } & Comercio & Desde 31 hasta 100 & Desde MXN 100.01 & 235 \\
\cline { 2 - 5 } & Servicios & Desde 51 hasta 100 & hasta MXN 250 & 250 \\
\cline { 2 - 5 } & Industria & Desde 51 hasta 250 & $\begin{array}{l}\text { Desde MXN 100.01 } \\
\text { hasta MXN 250 }\end{array}$ & 250 \\
\hline
\end{tabular}

Fuente. Diario Oficial de la Federación (2009).

Entre las contribuciones más importantes de las grandes empresas y su conglomerado a la producción mexicana, resaltan la petroquímica, la generación de productos eléctricos y electrónicos, así como de automóviles. Dichas empresas se caracterizan por la adopción de procesos de producción de alta tecnología y el énfasis que han puesto en el ahorro de energía y la disminución del consumo de materias primas, lo cual ha tenido efectos positivos en su desempeño ambiental.

Sin embargo, no es frecuente que este grupo de empresas se integre en asociaciones o cámaras industriales, lo cual significa una limitación para tener acceso a materias primas, a capacitación o a tecnologías apropiadas, en términos más favorables. Las pymes se encuentran mejor organizadas, en la mayor parte de los casos con empresarios que han realizado estudios profesionales y tienen un tipo de organización familiar basada más en enfoques paternalistas.

El sector manufacturero, de acuerdo con el Sistema de Clasificación Industrial de América del Norte, se encuentra dividido en 21 subsectores, 86 ramas, 182 subramas y 293 clases de actividades. Las industrias manufactureras están conformadas por unidades económicas dedicadas principalmente a la transformación mecánica física o química de materiales o sustancias, con el fin de obtener productos nuevos. También se consideran como parte de las manufacturas las actividades de maquila; el ensamble de partes y componentes o productos fabricados, la reconstrucción de maquinaria y equipo industrial, comercial, de oficina y otros, y el acabado de productos manufacturados mediante el teñido, el tratamiento calorífico, el enchapado y los procesos similares. Igualmente se incluye aquí la mezcla de materiales, como los aceites lubricantes, las resinas plásticas, las pinturas y los licores, entre otros.

Este sector se caracteriza por ser diversificado pues coexisten actividades altamente concentradas, como la industria siderúrgica, la automotriz, la de cemento, la elaboración de cerveza, la refinación de petróleo, por citar algunas, así como industrias atomizadas, por ejemplo la fabricación de productos de herrería, elaboración de pan, tortillas de maíz, purificación de agua, entre otras. 


\section{MiPyMEs en San Luis de Potosí}

as MiPyMEs representan alrededor del -mundo el segmento de la economía que aporta el mayor número de unidades económicas y personal ocupado, de ahí la relevancia de su desempeño, al incidir estas de manera fundamental en el comportamiento global de las economías nacionales (Martínez, 2012). A lo antes mencionado, el caso de
México no es la excepción. Como se observa (Tabla 2) son los establecimientos de 0 a 10 personas los que concentran el mayor número de unidades durante los tres censos económicos. El sector de la manufactura representa aproximadamente el $18 \%$ del total de personas ocupadas en los mismos tres censos económicos (Secretaría de Desarrollo Económico, 2015).

Tabla 2. Identificación de las empresas en México.

\begin{tabular}{|l|c|c|c|}
\hline & CE 2004 & CE 2009 & CE 2014 \\
\hline Número de establecimientos & 4290108 & 5144056 & 5664515 \\
\hline 0-10 personas & $95 \%$ & $95 \%$ & $95 \%$ \\
\hline $11-50$ personas & $3.9 \%$ & $4.0 \%$ & $4 \%$ \\
\hline $51-250$ personas & $0.9 \%$ & $0.8 \%$ & $0.8 \%$ \\
\hline Número de personas ocupadas & 3197214 & 27727406 & 29893584 \\
\hline Servicios no financieros & $45 \%$ & $47 \%$ & $49 \%$ \\
\hline Comercio & $25 \%$ & $26 \%$ & $24 \%$ \\
\hline Manufactura & $19 \%$ & $18 \%$ & $18 \%$ \\
\hline
\end{tabular}

CE: censo económico.

Fuente. Elaboración propia según Inegi (2014).

En su caso la distribución de unidades económicas en todo el país es a partir de cinco regiones, donde el estado de San Luis Potosí se encuentra ubicado en la región centro occidente. El sector manufacturero en dicha región se concentró en las unidades económicas del estrato micro con $92.2 \%$ del total de la región, mientras que el personal ocupado total y la producción bruta total se concentró en el estrato de empresas grandes con $44.2 \%$ y $73.1 \%$, respectivamente (Inegi, 2014). El Estado considera la industria manufacturera como un pilar económico; por ejemplo a 2015 dicha industria representó $62 \%$ del Producto Interno Bruto (PIB) del sector secundario y sus unidades económicas generaron $55.9 \%$ de los ingresos de la entidad (Comité de Planeación para el Desarrollo del Estado, 2015).

La industria manufacturera ha presentado una evolución positiva, debido al incremento porcentual, no solo de las unidades económicas o el total de personal ocupado, sino también en su significativo aumento del valor de la producción del censo económico de 1998 a 2014. En el censo económico de 1998 el valor bruto de la producción era de 45 657.3, y para 2014, de 196794 que representa un incremento porcentual de $76.7 \%$ (Tabla 3). 
Tabla 3. Características principales de la industria manufacturera en San Luis Potosí (2014).

\begin{tabular}{|l|c|c|c|c|}
\hline \multicolumn{1}{|c|}{ Concepto } & $\mathbf{1 9 9 8}$ & $\mathbf{2 0 0 3}$ & $\mathbf{2 0 0 8}$ & $\mathbf{2 0 1 4}$ \\
\hline Unidades económicas & 6412 & 6319 & 8113 & 8852 \\
\hline Total personal ocupado & 74387 & 87060 & 107892 & 125011 \\
\hline Valor bruto de la producción* & 45657 & 64824 & 130270 & 196794 \\
\hline Valor agregado censal bruto* & 14899 & 20155 & 38214 & 511330 \\
\hline
\end{tabular}

*Millones de pesos (MXN).

Fuente. Elaboración propia según Inegi, (1999, 2004, 2008 y 2014).

Al censo económico 2014, la indus- de las unidades económicas de las cuales, tria manufacturera sí cuenta con repre- en su conjunto, las MiPyMEs figuran con sentatividad en el Estado y concentra $74 \% 99 \%$ (Tabla 4; Tabla 5).

Tabla 4. Participación de unidades económicas y personal ocupado total por sector económico en San Luis Potosí (2014).

\begin{tabular}{|l|l|l|l|l|}
\hline \multirow{2}{*}{ Sector } & \multicolumn{2}{c|}{$\begin{array}{c}\text { Unidades } \\
\text { económicas }\end{array}$} & \multicolumn{2}{c|}{$\begin{array}{c}\text { Personal } \\
\text { ocupado total }\end{array}$} \\
\cline { 2 - 5 } & Absoluto & \multicolumn{1}{c|}{$\%$} & Absoluto & \multicolumn{1}{c|}{$\%$} \\
\hline Total nacional & 88153 & 100 & 420246 & 100 \\
\hline $\begin{array}{l}\text { Total industrias manufactureras, } \\
\text { comercio y servicios privados no } \\
\text { financieros }\end{array}$ & 86558 & 98 & 385261 & 92 \\
\hline Industrias manufactureras & 41640 & 74 & 124897 & 30 \\
\hline Comercio & 36066 & 41 & 135353 & 32 \\
\hline Servicio privados no financieros & 8852 & 10 & 125011 & 30 \\
\hline Resto de actividades & 1595 & 2 & 34985 & 8 \\
\hline
\end{tabular}

Fuente. Inegi, (2014).

Tabla 5. Participación en unidades económicas y personal ocupado total de la industria manufacturera en San Luis Potosí, (2014).

\begin{tabular}{|l|c|c|c|c|}
\hline \multirow{2}{*}{\multicolumn{1}{|c|}{ Tamaño }} & \multicolumn{2}{c|}{$\begin{array}{c}\text { Unidades } \\
\text { económicas }\end{array}$} & \multicolumn{2}{c|}{$\begin{array}{c}\text { Personal ocupado } \\
\text { total }\end{array}$} \\
\cline { 2 - 5 } & Absoluto & \% & Absoluto & \% \\
\hline Total & 8852 & 100.0 & 125011 & 100.0 \\
\hline Total mipymes & 8751 & 99 & 50833 & 40.7 \\
\hline Micro & 8162 & 92 & 19959 & 16.0 \\
\hline Pequeña & 410 & 5 & 9319 & 7.5 \\
\hline Mediana & 179 & 2 & 21555 & 17.2 \\
\hline Grande & 101 & 1 & 74178 & 59.3 \\
\hline
\end{tabular}

Fuente. Elaboración propia a partir de Censos Económicos, (1999, 2004, 2008 y 2009). 
Dentro de la industria manufacturera, destaca la fabricación de equipo automotor y autopartes, que representa $70.9 \%$ de las mercancías exportadas por esta actividad, así como la manufactura de maquinaria y equipo, las industrias metálicas básicas, la fabricación de productos a base de minerales no metálicos y la industria alimentaria (Comité de Planeación para el Desarrollo del Estado, 2015).

\section{Metodología del estudio}

\subsection{Pregunta de investigación, objetivo, hipótesis e instrumentos de recolección de datos}

El objetivo de esta investigación fue determinar la relación que existe entre el nivel de financiamiento, la capacitación, el entrenamiento por parte del empresario y el crecimiento sostenido de las pequeñas empresas industriales en San Luis Potosí. La pregunta central de investigación fue esta: ¿cuál es la relación del entrenamiento, la capacitación y el financiamiento con el crecimiento sostenido para las pequeñas empresas industriales en San Luis Potosí? Consecuentemente, la hipótesis giró en torno a la afirmación de que existe una relación directa entre la capacitación, el entrenamiento y el nivel de financiamiento como factores que influyen en el crecimiento sostenido de las pequeñas empresas industriales en San Luis Potosí. Las hipótesis son:

- Los niveles de capacitación, entrenamiento y financiamiento no son determinantes para que una pequeña empresa llegue a un crecimiento sostenido.

- Los pequeños empresarios carecen de la información necesaria para poder resolver los problemas que se presentan en las pequeñas empresas, que permita garantizar un crecimiento dentro de los siguientes cinco años de vida.
- No existe una relación directa entre el nivel de entrenamiento por parte de los empresarios y el crecimiento sostenido de la pequeña empresa del sector industrial de San Luis Potosí.

- No existe una relación directa entre el nivel de capacitación de los empresarios y el personal que trabaja dentro de la pequeña empresa con el crecimiento sostenido de esta.

- La relación directa entre el nivel de financiamiento que cuenta la empresa y el crecimiento sostenido de la pequeña empresa es inexistente.

En esta investigación se pretende usar los análisis cuantitativos siguientes: la encuesta: preguntas cerradas, abiertas y de opción múltiple para conocer si han tenido algún tipo de problema y analizar si son originados por las variables de estudio en esta investigación.

\subsection{Identificación de las variables}

Para esta investigación se examinaron los siguientes grupos de variables:

- Capacitación del empresario: es todo estudio formal que tiene el empresario de característica principal escolarizado y se rige por una calificación, es impartido por una institución educativa con reconocimiento oficial y se encuentra bajo un sistema. Las variables que conforman este grupo son del tipo categóricas ordinales: 
Tabla 6. Grupo de variables 1: capacitación del empresario.

\begin{tabular}{|l|l|}
\hline \multicolumn{1}{|c|}{ Nivel de estudios } & Tipo de variable \\
\hline Primaria & Básico \\
\hline Secundaria & Básico \\
\hline Preparatoria/bachillerato técnico & Nivel medio superior \\
\hline Licenciatura & Nivel superior \\
\hline Especialidades & Posgrado \\
\hline Maestría & Posgrado \\
\hline Doctorado & Posgrado \\
\hline
\end{tabular}

Fuente. Elaboración propia.

- Entrenamiento del empresario: son todas las habilidades y los conocimientos no formales adquiridos por el empresario a lo largo de su vida profesional y que no se rigen por un sistema de estudios formales (Tabla 7).

Tabla 7. Grupo de variables 2: entrenamiento del empresario.

\begin{tabular}{|l|l|}
\hline \multicolumn{1}{|c|}{ Años de experiencia } & \multicolumn{1}{c|}{$\begin{array}{c}\text { Tipo de } \\
\text { variable }\end{array}$} \\
\hline Tiempo & Continua \\
\hline Número de documentos recopilados & Discreta \\
\hline Número de puestos ocupados & Discreta \\
\hline Cursos asistidos & Discreta \\
\hline Diplomados & Discreta \\
\hline Pláticas formales & Discreta \\
\hline Pláticas informales & Discreta \\
\hline Congresos & Discreta \\
\hline Lecturas críticas especializadas & Discreta \\
\hline
\end{tabular}

Fuente. Elaboración propia.

- Nivel académico de todos los integrantes de la empresa: es todo estudio formal que tienen los integrantes de la empresa y que tiene como característica principal que son estudios escolarizados y se rigen por una calificación, son impartidos por una institución educativa con reconocimiento oficial y se encuentran bajo un sistema calendarizado.

- Financiamiento en los primeros años de vida: es el dinero que se encuentra disponible para solventar los gastos propios de la empresa (Tabla 8).

Tabla 8. Grupo de variables 3: financiamiento en los primeros años de vida.

\begin{tabular}{|l|c|}
\hline & Tipo de variable \\
\hline Total de ingresos obtenido en el año & Discreta \\
\hline Circulante disponible & Discreta \\
\hline Nivel de endeudamiento & Discreta \\
\hline
\end{tabular}

Fuente. Elaboración propia. 
El objetivo principal de la investigación es ver la interacción que existe entre las variables independientes y las variables dependientes. Se pretende analizar cómo afectan las variables independientes a la variable dependiente en las pequeñas empresas en los primeros cinco años de vida para su permanencia en el mercado, crecimiento o cierre de ellas, ya que una empresa puede tener controlada una variable, lo cual no significa que se pueda decir que sus problemas son menos o que no va a tener problema alguno. La variable dependiente es el crecimiento sostenido.

- Crecimiento sostenido: es la permanencia o el éxito del mercado que tienen las pequeñas empresas dentro de los primeros cinco años de vida. Se va a ver el crecimiento en el nivel de ventas, el crecimiento que tienen año a año, el flujo de efectivo con el que cuenta la empresa, el nivel de posicionamiento en el mercado en que se encuentra la empresa, el número de personas con el que cuenta la empresa y el nivel de rotación de personal.

La muestra no fue aleatoria debido a que no se contaba con la aceptación de la participación de todo el universo que conforman las pequeñas empresas del sector industrial de San Luis Potosí. En colaboración con la Cámara Nacional de la Industria de la Transformación del Estado, se consultaron a 50 empresas para ser consideradas en la investigación. Solo aceptaron participar 30, validando así un comportamiento hacia lo normal dentro de las bases de la estadística.

\subsection{Determinación de la técnica de análisis de correlación}

La clasificación que se hizo con las variables independientes es a priori, donde se tomó en cuenta una característica en general para poder hacer la separación de las variables. Con el propósito de saber si es la mejor clasificación se realizó un análisis correlacional para determinar la intensidad de la relación entre dos o más variables. Después de encontrar la mejor clasificación y distribución de las variables independientes, se procedió a efectuar el análisis de regresión múltiple para analizar la relación entre la única variable criterio y las varias variables independientes. El objeto de utilizar este análisis es usar las variables independientes cuyos valores pueden predecir la única dependiente seleccionada. En esta investigación, existen dos tipos de variables: i) variables cualitativas -capacitación y entrenamiento-y ii) variables métricas -financiamiento-. El modelo de regresión múltiple nos sirve para evaluar la contribución de cada conjunto de variables, como serían las variables de capacitación, entrenamiento y financiamiento.

El objetivo de la investigación es ver cómo se relacionan los grupos de variables para garantizar el éxito de la pequeña empresa. Es una garantía si un empresario cuenta con una sola de las características de las variables independientes. No es seguro que tenga un crecimiento sostenido, debido a que el crecimiento es una mezcla de todas las variables. La fórmula de interpretación utilizada fue:

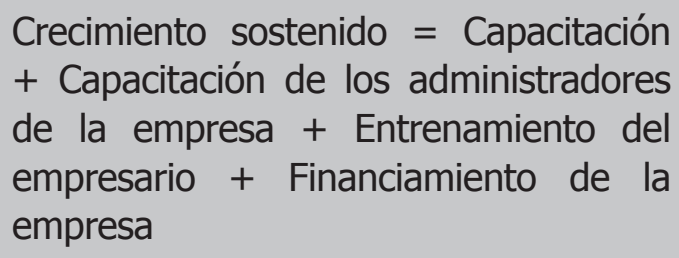
de la empresa + Entrenamiento del empresario + Financiamiento de la empresa

Después vendría a determinar si existe una relación significativa entre las variables independientes y la variable dependiente. 
$\mathrm{H}_{0}: \mathrm{B}_{1}=\mathrm{B}_{2}=\mathrm{B}_{3}=\mathrm{B}_{4}=0$-no existe una relación entre el éxito y las variables independientes-.

$\mathrm{H}_{1}$ : Al menos una de las variables inde-pendientes no son igual a 0.

Por otro lado, se trabajará con un nivel de significancia de 0.05 .

\section{Resultados}

\subsection{Análisis descriptivo}

Los resultados estadísticos de la encuesta presentada a la muestra seleccionada para el estudio de las pequeñas empresas del sector industrial de San Luis Potosí revelan que, con relación a la variable de Capacitación, $54 \%$ de los encuestados posee una antigüedad de entre uno y diez años en su organización; el máximo grado de estudios predominante entre los administradores es la licenciatura, con $67 \%$; el nivel de estudios de los operarios en su mayoría es de nivel secundaria, con $53 \%$; de los supervisores, $60 \%$ es de nivel preparatoria; y el nivel de estudios del director es de licenciatura, con $70 \%$. Finalmente, $53 \%$ de los encuestados está de acuerdo con que su formación académica les ha permitido identificar y resolver los principales problemas y $50 \%$ concuerda en que la actividad de su empresa y su formación académica se encuentran relacionadas.

Relacionado con la variable de Entrenamiento, se pudo observar que $43 \%$ de los encuestados opina que su experiencia profesional corresponde en gran medida a sus estudios realizados, por tanto, se encontró dentro del estudio, que la relación entre la experiencia laboral y la principal actividad de la empresa se encuentran muy relacionadas. El $76 \%$ de las personas encuestadas poseen un hábito de lectura, y de ellos $67 \%$, se encuentran suscritas a alguna revista afín del giro de su empresa. Del total de encuestados, solo $37 \%$ de los encuestados asiste de manera regular a congresos donde se traten temas afines con el giro de la empresa. El $67 \%$ se encuentra afiliado a alguna cámara relacionada con el giro de la empresa y $47 \%$ de los encuestados pertenece a la Cámara Nacional de la Industria de Transformación. El $36 \%$ del total de la muestra se encuentra un poco de acuerdo en que los problemas son originados por falta de capacitación o información por parte de ellos y $50 \%$ de los encuestados considera que los problemas son originados por causas externas.

Con relación a la variable de Financiamiento, $57 \%$ y $63 \%$ de los encuestados opina que sus utilidades han ido en aumento y que el comportamiento de los activos ha ido en aumento en el mismo periodo de tiempo. El $90 \%$ respondió que conoce la importancia de los financiamientos, pero solo $67 \%$ ha solicitado uno y $68 \%$ tuvo la fuente de financiamiento con la iniciativa privada. El $53 \%$ afirma no conocer los apoyos brindados por Gobierno. La respuesta con porcentaje mayor $-30 \%$ - afirma que fue solicitado para comprar maquinaria o equipo. El 56.7 $\%$ considera el nivel de efectivo que circula de las empresas como bueno y $70 \%$ de las empresas reinvierte el efectivo sobrante. 


\subsection{Análisis de correlaciones de Spearman}

A continuación, se muestran los resultados de las correlaciones no paramétricas para las variables de capacitación (Tabla 9).

Tabla 9. Correlaciones no paramétricas para la capacitación

\begin{tabular}{|c|c|c|c|c|c|c|}
\hline & & $\begin{array}{c}\text { En los } \\
\text { últimos cinco } \\
\text { años, ¿cómo } \\
\text { han sido las } \\
\text { utilidades de } \\
\text { la empresa? }\end{array}$ & $\begin{array}{c}\text { En los últimos } \\
\text { cinco años, } \\
\text { ¿cuál ha sido el } \\
\text { comportamiento } \\
\text { de la planta } \\
\text { laboral de } \\
\text { trabajo? }\end{array}$ & $\begin{array}{c}\text { En los } \\
\text { últimos } \\
\text { cinco años, } \\
\text { ¿cómo } \\
\text { han sido } \\
\text { los activos } \\
\text { de la } \\
\text { empresa? }\end{array}$ & \begin{tabular}{|c} 
Lee \\
actualmente \\
revistas \\
especializadas \\
en el giro de \\
la empresa
\end{tabular} & $\begin{array}{c}\text { La relación } \\
\text { entre su } \\
\text { experiencia } \\
\text { laboral y } \\
\text { la principal } \\
\text { actividad de } \\
\text { la empresa } \\
\text { es... }\end{array}$ \\
\hline \multirow{3}{*}{$\begin{array}{l}\text { En los últimos } \\
\text { cinco años, } \\
\text { ¿cómo han sido } \\
\text { las utilidades de } \\
\text { la empresa año a } \\
\text { año? }\end{array}$} & $\begin{array}{l}\text { Coeficiente de } \\
\text { correlación }\end{array}$ & 1.000 & $0.634(* *)$ & $0.442\left(^{*}\right)$ & -0.239 & 0.206 \\
\hline & Sig. (bilateral) & & 0.000 & 0.015 & 0.204 & 0.276 \\
\hline & N & 30 & 30 & 30 & 30 & 30 \\
\hline \multirow{3}{*}{$\begin{array}{l}\text { En los últimos } \\
\text { cinco años, } \\
\text { ¿cuál ha sido el } \\
\text { comportamiento } \\
\text { de la planta } \\
\text { laboral de } \\
\text { trabajo? }\end{array}$} & $\begin{array}{l}\text { Coeficiente de } \\
\text { correlación }\end{array}$ & $0.634(* *)$ & 1.000 & $0.650(* *)$ & -0.015 & 0.133 \\
\hline & Sig. (bilateral) & 0.000 & 0.000 & 0.000 & 0.936 & 0.483 \\
\hline & N & 30 & 30 & 30 & 30 & 30 \\
\hline \multirow{3}{*}{$\begin{array}{l}\text { En los últimos } \\
\text { cinco años, } \\
\text { ¿cómo han sido } \\
\text { los activos de la } \\
\text { empresa? }\end{array}$} & $\begin{array}{l}\text { Coeficiente de } \\
\text { correlación }\end{array}$ & $0.442\left(^{*}\right)$ & $0.650(* *)$ & 1.000 & 0.090 & 0.066 \\
\hline & Sig. (bilateral) & 0.015 & 0.000 & 0.000 & 0.636 & 0.728 \\
\hline & N & 30 & 30 & 30 & 30 & 30 \\
\hline \multirow{3}{*}{$\begin{array}{l}\text { Lee actualmente } \\
\text { revistas } \\
\text { especializadas } \\
\text { en el giro de la } \\
\text { empresa }\end{array}$} & \begin{tabular}{|l|}
$\begin{array}{l}\text { Coeficiente de } \\
\text { correlación }\end{array}$ \\
\end{tabular} & -0.239 & -0.015 & 0.090 & 1.000 & 0.172 \\
\hline & Sig. (bilateral) & 0.204 & 0.936 & 0.636 & 0.000 & 0.365 \\
\hline & $\mathrm{N}$ & 30 & 30 & 30 & 30 & 30 \\
\hline \multirow{3}{*}{$\begin{array}{l}\text { La relación entre } \\
\text { su experiencia } \\
\text { laboral y } \\
\text { la principal } \\
\text { actividad de la } \\
\text { empresa es... }\end{array}$} & $\begin{array}{l}\text { Coeficiente de } \\
\text { correlación }\end{array}$ & 0.206 & 0.133 & 0.066 & 0.172 & 1.000 \\
\hline & Sig. (bilateral) & 0.276 & 0.483 & 0.728 & 0.365 & 0.000 \\
\hline & N & 30 & 30 & 30 & 30 & 30 \\
\hline
\end{tabular}

**La correlación es significativa al nivel 0.01 (bilateral).

*La correlación es significativa al nivel 0.05 (bilateral).

Fuente. Elaboración propia. 
Se presentan las correlaciones no paramétricas para la variable de crecimiento contra la de diplomados y congresos (Tabla 10).

Tabla 10. Correlaciones no paramétricas de crecimiento contra la de diplomados y congresos

\begin{tabular}{|c|c|c|c|c|c|c|c|}
\hline & $\begin{array}{c}\text { En los } \\
\text { últimos } \\
\text { cinco } \\
\text { años, } \\
\text { ¿cómo han } \\
\text { sido las } \\
\text { utilidades } \\
\text { de la } \\
\text { empresa? }\end{array}$ & $\begin{array}{l}\text { En los últimos } \\
\text { cinco años, } \\
\text { ¿cuál ha sido el } \\
\text { comportamiento } \\
\text { de la planta } \\
\text { laboral de } \\
\text { trabajo? }\end{array}$ & $\begin{array}{c}\text { En los } \\
\text { últimos } \\
\text { cinco } \\
\text { años, } \\
\text { ¿cómo } \\
\text { han sido } \\
\text { los activos } \\
\text { de la } \\
\text { empresa? }\end{array}$ & $\begin{array}{l}\text { ¿Asiste a } \\
\text { congresos } \\
\text { donde } \\
\text { se traten } \\
\text { temas } \\
\text { afines del } \\
\text { giro de la } \\
\text { empresa? }\end{array}$ & $\begin{array}{c}\text { ¿Ha } \\
\text { asistido a } \\
\text { diplomados } \\
\text { donde } \\
\text { se traten } \\
\text { temas de } \\
\text { importancia } \\
\text { para la } \\
\text { empresa? }\end{array}$ \\
\hline \multirow{15}{*}{$\begin{array}{l}\text { Rho de } \\
\text { Spearman }\end{array}$} & \multirow{3}{*}{$\begin{array}{l}\text { En los últimos } \\
\text { cinco años, } \\
\text { ¿cómo han } \\
\text { sido las } \\
\text { utilidades de la } \\
\text { empresa año } \\
\text { con año? } \\
\end{array}$} & $\begin{array}{l}\text { Coeficiente } \\
\text { de } \\
\text { correlación }\end{array}$ & 1.000 & $0.634(* *)$ & $0.442(*)$ & 0.021 & 0.010 \\
\hline & & $\begin{array}{l}\text { Sig. } \\
\text { (bilateral) }\end{array}$ & 0.000 & 0.000 & 0.015 & 0.913 & 0.957 \\
\hline & & $\mathrm{N}$ & 30 & 30 & 30 & 30 & 30 \\
\hline & \multirow{3}{*}{$\begin{array}{l}\text { En los últimos } \\
\text { cinco años, } \\
\text { ¿cuál ha sido } \\
\text { el comporta- } \\
\text { miento de la } \\
\text { planta laboral } \\
\text { de trabajo? }\end{array}$} & $\begin{array}{l}\text { Coeficiente } \\
\text { de } \\
\text { correlación }\end{array}$ & $0.634(* *)$ & 1.000 & $0.650(* *)$ & 0.190 & 0.133 \\
\hline & & $\begin{array}{l}\text { Sig. } \\
\text { (bilateral) }\end{array}$ & 0.000 & 0.000 & 0.000 & 0.315 & 0.485 \\
\hline & & $\mathrm{N}$ & 30 & 30 & 30 & 30 & 30 \\
\hline & \multirow{3}{*}{$\begin{array}{l}\text { En los últimos } \\
\text { cinco años, } \\
\text { ¿cómo han } \\
\text { sido los } \\
\text { activos de la } \\
\text { empresa? }\end{array}$} & $\begin{array}{l}\text { Coeficiente } \\
\text { de } \\
\text { correlación }\end{array}$ & $0.442(*)$ & $0.650(* *)$ & 1.000 & 0.244 & 0.334 \\
\hline & & $\begin{array}{l}\text { Sig. } \\
\text { (bilateral) }\end{array}$ & 0.015 & 0.000 & 0.000 & 0.194 & 0.071 \\
\hline & & $\mathrm{N}$ & 30 & 30 & 30 & 30 & 30 \\
\hline & \multirow{3}{*}{\begin{tabular}{|l|} 
¿Asiste usted \\
a congresos \\
donde se \\
traten temas \\
afines del \\
giro de la \\
empresa? \\
\end{tabular}} & $\begin{array}{l}\text { Coeficiente } \\
\text { de } \\
\text { correlación }\end{array}$ & 0.021 & 0.190 & 0.244 & 1.000 & $0.498(* *)$ \\
\hline & & $\begin{array}{l}\text { Sig. } \\
\text { (bilateral) }\end{array}$ & 0.913 & 0.315 & 0.194 & 0.000 & 0.005 \\
\hline & & N & 30 & 30 & 30 & 30 & 30 \\
\hline & \multirow{3}{*}{$\begin{array}{l}\text { ¿Ha asistido } \\
\text { a diplomados } \\
\text { donde se } \\
\text { traten temas } \\
\text { de importancia } \\
\text { para la } \\
\text { empresa? }\end{array}$} & $\begin{array}{l}\text { Coeficiente } \\
\text { de } \\
\text { correlación }\end{array}$ & 0.010 & 0.133 & 0.334 & $0.498(* *)$ & 1.000 \\
\hline & & \begin{tabular}{|l|} 
Sig. \\
(bilateral)
\end{tabular} & 0.957 & 0.485 & 0.071 & 0.005 & 0.000 \\
\hline & & $\mathrm{N}$ & 30 & 30 & 30 & 30 & 30 \\
\hline
\end{tabular}

*La correlación es significativa al nivel 0.05 (bilateral).

**La correlación es significativa al nivel 0.01 (bilateral).

Fuente. Elaboración propia. 
A continuación, se muestra las correlaciones no paramétricas de administradores y directivos contra la de crecimiento.

Tabla 11. Correlaciones no paramétricas de administradores y directivos contra el crecimiento

\begin{tabular}{|c|c|c|c|c|c|c|c|}
\hline & & & $\begin{array}{c}\text { En los } \\
\text { últimos } \\
\text { cinco } \\
\text { años, } \\
\text { ¿cómo han } \\
\text { sido las } \\
\text { utilidades } \\
\text { de la } \\
\text { empresa } \\
\text { en los } \\
\text { últimos } \\
\text { cinco } \\
\text { años? } \\
\end{array}$ & $\begin{array}{c}\text { En los } \\
\text { últimos } \\
\text { cinco años, } \\
\text { ¿cuál ha } \\
\text { sido el } \\
\text { comporta- } \\
\text { miento de } \\
\text { la planta } \\
\text { laboral de } \\
\text { trabajo? }\end{array}$ & $\begin{array}{c}\text { En los } \\
\text { últimos } \\
\text { cinco } \\
\text { años, } \\
\text { ¿cómo han } \\
\text { sido los } \\
\text { activos de } \\
\text { la empresa } \\
\text { en los } \\
\text { últimos } \\
\text { cinco } \\
\text { años? }\end{array}$ & $\begin{array}{l}\text { Máximo } \\
\text { nivel de la } \\
\text { persona } \\
\text { enfrente } \\
\text { de la } \\
\text { adminis- } \\
\text { tración en } \\
\text { grado }\end{array}$ & $\begin{array}{c}\text { Máximo } \\
\text { nivel del } \\
\text { director } \\
\text { de la } \\
\text { empresa } \\
\text { en grados }\end{array}$ \\
\hline \multirow{15}{*}{$\begin{array}{c}\text { Rho de } \\
\text { Spearman }\end{array}$} & \multirow{3}{*}{$\begin{array}{l}\text { En los últimos } \\
\text { cinco años, } \\
\text { ¿cómo han sido } \\
\text { las utilidades de } \\
\text { la empresa año } \\
\text { con año? }\end{array}$} & $\begin{array}{l}\text { Coeficiente de } \\
\text { correlación }\end{array}$ & 1.000 & $0.634(* *)$ & $0.442(*)$ & 0.065 & 0.234 \\
\hline & & Sig. (bilateral) & 0.000 & 0.000 & 0.015 & 0.731 & 0.212 \\
\hline & & $\mathrm{N}$ & 30 & 30 & 30 & 30 & 30 \\
\hline & \multirow{3}{*}{$\begin{array}{l}\text { En los últimos } \\
\text { cinco años, } \\
\text { ¿cuál ha sido el } \\
\text { comportamiento } \\
\text { de la planta } \\
\text { laboral de } \\
\text { trabajo? }\end{array}$} & $\begin{array}{l}\text { Coeficiente de } \\
\text { correlación }\end{array}$ & $0.634(* *)$ & 1.000 & $0.650(* *)$ & -0.073 & 0.276 \\
\hline & & Sig. (bilateral) & 0.000 & 0.000 & 0.000 & 0.701 & 0.140 \\
\hline & & $\mathrm{N}$ & 30 & 30 & 30 & 30 & 30 \\
\hline & \multirow{3}{*}{$\begin{array}{l}\text { En los últimos } \\
\text { cinco años, } \\
\text { ¿cómo han sido } \\
\text { los activos de la? }\end{array}$} & $\begin{array}{l}\text { Coeficiente de } \\
\text { correlación }\end{array}$ & $0.442(*)$ & $0.650(* *)$ & 1.000 & -0.007 & 0.217 \\
\hline & & Sig. (bilateral) & 0.015 & 0.000 & 0.000 & 0.973 & 0.249 \\
\hline & & $\mathrm{N}$ & 30 & 30 & 30 & 30 & 30 \\
\hline & \multirow{3}{*}{$\begin{array}{l}\text { Máximo nivel } \\
\text { de la persona } \\
\text { enfrente de la } \\
\text { administración } \\
\text { en grado }\end{array}$} & $\begin{array}{l}\text { Coeficiente de } \\
\text { correlación }\end{array}$ & 0.065 & -0.073 & -0.007 & 1.000 & $0.660\left(^{* *}\right)$ \\
\hline & & Sig. (bilateral) & 0.731 & 0.701 & 0.973 & 0.000 & 0.000 \\
\hline & & $\mathrm{N}$ & 30 & 30 & 30 & 30 & 30 \\
\hline & \multirow{3}{*}{$\begin{array}{l}\text { Máximo nivel } \\
\text { del director de } \\
\text { la empresa en } \\
\text { grados }\end{array}$} & $\begin{array}{l}\text { Coeficiente de } \\
\text { correlación }\end{array}$ & 0.234 & 0.276 & 0.217 & $0.660(* *)$ & 1.000 \\
\hline & & Sig. (bilateral) & 0.212 & 0.140 & 0.249 & 0.000 & 0.000 \\
\hline & & $\mathrm{N}$ & 30 & 30 & 30 & 30 & 30 \\
\hline
\end{tabular}

*La correlación es significativa al nivel 0.05 (bilateral).

**La correlación es significativa al nivel 0.01 (bilateral).

Fuente. Elaboración propia. 
En seguida se presentan las correlaciones no paramétricas del entrenamiento de operarios (Tabla 12).

Tabla 12. Correlaciones no paramétricas del entrenamiento de operarios.

\begin{tabular}{|c|c|c|c|c|c|c|}
\hline & & $\begin{array}{c}\text { En los } \\
\text { últimos } \\
\text { cinco } \\
\text { años, } \\
\text { ¿cómo han } \\
\text { sido las } \\
\text { utilidades } \\
\text { de la } \\
\text { empresa? }\end{array}$ & $\begin{array}{l}\text { En los últimos } \\
\text { cinco años, } \\
\text { ¿cuál ha sido el } \\
\text { comportamiento } \\
\text { de la planta } \\
\text { laboral de } \\
\text { trabajo? }\end{array}$ & $\begin{array}{l}\text { En los últimos } \\
\text { cinco años, } \\
\text { ¿cómo han } \\
\text { sido los activos } \\
\text { de la empresa? }\end{array}$ & $\begin{array}{l}\text { ¿Aproxima- } \\
\text { damente } \\
\text { cuál es el } \\
\text { nivel de } \\
\text { estudios } \\
\text { de los } \\
\text { operarios? }\end{array}$ & $\begin{array}{l}\text { ¿Aproximada- } \\
\text { mente cuál } \\
\text { es el nivel de } \\
\text { estudios de los } \\
\text { supervisores? }\end{array}$ \\
\hline \multirow{3}{*}{$\begin{array}{l}\text { En los últimos } \\
\text { cinco años, ¿cómo } \\
\text { han sido las } \\
\text { utilidades de la } \\
\text { empresa? }\end{array}$} & $\begin{array}{c}\text { Coeficiente } \\
\text { de correlación }\end{array}$ & 1.000 & $0.634(* *)$ & $0.442(*)$ & 0.230 & 0.190 \\
\hline & Sig. (bilateral) & 0.000 & 0.000 & 0.015 & 0.221 & 0.352 \\
\hline & $\mathrm{N}$ & 30 & 30 & 30 & 30 & 26 \\
\hline \multirow{3}{*}{$\begin{array}{l}\text { En los últimos } \\
\text { cinco años, } \\
\text { ¿cuál ha sido el } \\
\text { comportamiento } \\
\text { de la planta laboral } \\
\text { de trabajo? }\end{array}$} & $\begin{array}{c}\text { Coeficiente } \\
\text { de correlación }\end{array}$ & $0.634(* *)$ & 1.000 & $0.650(* *)$ & 0.093 & 0.037 \\
\hline & Sig. (bilateral) & 0.000 & 0.000 & 0.000 & 0.624 & 0.859 \\
\hline & N & 30 & 30 & 30 & 30 & 26 \\
\hline \multirow{3}{*}{$\begin{array}{l}\text { En los últimos } \\
\text { cinco años, } \\
\text { ¿cómo han sido } \\
\text { los activos de la } \\
\text { empresa? }\end{array}$} & $\begin{array}{c}\text { Coeficiente } \\
\text { de correlación }\end{array}$ & $0.442(*)$ & $0.650(* *)$ & 1.000 & 0.066 & 0.204 \\
\hline & Sig. (bilateral) & 0.015 & 0.000 & 0.000 & 0.728 & 0.316 \\
\hline & $\mathrm{N}$ & 30 & 30 & 30 & 30 & 26 \\
\hline \multirow{3}{*}{$\begin{array}{l}\text { ¿Aproximadamente } \\
\text { cuál es el nivel de } \\
\text { estudios de los } \\
\text { operarios? }\end{array}$} & $\begin{array}{c}\text { Coeficiente } \\
\text { de correlación }\end{array}$ & 0.230 & 0.093 & 0.066 & 1.000 & $.672(* *)$ \\
\hline & Sig. (bilateral) & 0.221 & 0.624 & 0.728 & 0.000 & 0.000 \\
\hline & $\mathrm{N}$ & 30 & 30 & 30 & 30 & 26 \\
\hline \multirow{3}{*}{$\begin{array}{l}\text { ¿Aproximadamente } \\
\text { cuál es el nivel de } \\
\text { estudios de los } \\
\text { supervisores? }\end{array}$} & $\begin{array}{c}\text { Coeficiente } \\
\text { de correlación }\end{array}$ & 0.190 & 0.037 & 0.204 & $0.672(* *)$ & 1.000 \\
\hline & Sig. (bilateral) & 0.352 & 0.859 & 0.316 & 0.000 & 0.000 \\
\hline & $\mathrm{N}$ & 26 & 26 & 26 & 26 & 26 \\
\hline
\end{tabular}

*La correlación es significativa al nivel 0.05 (bilateral).

**La correlación es significativa al nivel 0.01 (bilateral).

Fuente. Elaboración propia. 


\section{Conclusiones}

Esta investigación aportó un mayor cono- cimiento de la situación que se vive en las pequeñas empresas industriales que se encuentran localizadas en San Luis Potosí con relación a las variables estudiadas -Nivel de capacitación, Entrenamiento, Financiamiento y Crecimiento sostenido de la empresa-. Su objetivo fue determinar la relación que existe entre el nivel de financiamiento, la capacitación, el entrenamiento por parte del empresario y el crecimiento sostenido de las pequeñas empresas indus-triales en San Luis Potosí.

Dentro del mismo estudio, además, podemos ver que $93 \%$ de las personas que se encuentran al frente de la administración de pequeñas empresas cuentan con una preparación de estudios de nivel superior o posgrados y que $53 \%$ está de acuerdo con que su formación académica les ha permitido identificar y resolver los principales problemas de la empresa. El $87 \%$ de la muestra dice que el director de la empresa cuenta con estudios de nivel superior o posgrado y $50 \%$ concuerda en que la actividad de su empresa y su formación académica se encuentran relacionados.

Con respecto a la variable de entrenamiento, todos los estudios no formales y experiencia influyen dentro del manejo de las pequeñas empresas. Se observa que $43 \%$ de las personas que están en la administración opinan que su experiencia profesional corresponde en gran medida a sus estudios realizados. En el análisis que se llevó a cabo, se puede observar que la experiencia laboral y la principal actividad de la empresa se encuentran muy relacionadas pues los administradores están preocupados por tener a la mano lecturas especializadas que les permitan tener una mejor visión sobre el rumbo que debe de tener la empresa.

Para la variable de Financiamiento; se observó que los empresarios y administradores de las pequeñas empresas encuestadas conocen la importancia de los financiamientos. El $67 \%$ ha solicitado un financiamiento, $30 \%$ tiene su origen en la iniciativa privada, mientras que $27 \%$ pertenece al sector público. Las empresas que han solicitado un financiamiento se debe a la necesidad de comprar maquinaria o equipo.

Podemos concluir que para las pequeñas empresas que pertenecen al sector industrial en las que se centra el estudio, es de carácter primordial contar con un nivel de flujo económico para poder ver un crecimiento dentro de las utilidades, lo cual permite poder afrontar los compromisos inmediatos de la empresa mediante la reducción de pasivo y una mayor cobertura dentro de los insumos, ya que en la inversión del efectivo para la adquisición de activos no genera el mismo incremento en las utilidades. Dentro de la relación de empresas que han solicitado préstamos para el financiamiento de sus operaciones, solo $16 \%$ del total de la muestra reporta que sus utilidades han aumentado en los últimos cinco años derivados de la adquisición de estos préstamos.

En casi $64 \%$ de la muestra estudiada se encuentra que las pequeñas empresas que han tenido incrementos en su planta laboral 
en los últimos cinco años reportan que de igual forma su utilidades han incrementado, con lo cual se comprueba que existe una relación directamente proporcional: la empresa tiene un crecimiento sostenido cuando sus utilidades son afectadas de manera positiva en relación con su fuerza laboral. De igual manera, existe una relación de $44 \%$ de las empresas que tienen un incremento en los últimos años en sus activos, reflejados también en un crecimiento en las utilidades.

Además, en cuanto al crecimiento sostenido que se maneja en la muestra de empresas seleccionadas, su crecimiento en activos, fuerza laboral y el incremento en sus utilidades no han sido generados por financiamientos externos. Lo anterior lo podemos observar en la misma tabla de correlaciones, que el incremento en utilidades con la solicitud de financiamientos es de signo contrario, es decir que, en lugar de tener mayor número de utilidades derivadas por la solicitud de un préstamo externo, su crecimiento en estas mismas son negativas, y el incremento en planta laboral y de activos es prácticamente nulo.

En la relación que existe entre la variable de la experiencia laboral como un factor determinante en el crecimiento, encontramos una correlación de 0.206 entre las utilidades y la experiencia, lo cual quiere decir que, cuanto más se encuentre relacionada la experiencia laboral con la actividad de la empresa, mayor será el índice de utilidades; mientras que la relación entre el comportamiento de la planta y la experiencia laboral también muestra un coeficiente positivo de 0.133 . De esta forma, nos damos cuenta de que, a mayor relación entre la actividad de la empresa y la experiencia laboral, mejores resultados obtendrán las empresas respecto de su personal; sin embargo, la correlación entre el crecimiento de activos y la experiencia profesional es muy débil y alcanza apenas 0.066. De lo anterior podemos inferir que esta relación no es mala, sino, al contrario, que una persona con mayor experiencia en el ramo puede llegar a la optimización de sus recursos y no siempre buscar un crecimiento de su empresa con la adquisición de más activos.

Finalmente, la comprobación de hipótesis se expresa como sigue:

- Existe una relación directa entre el nivel de entrenamiento por parte de los empresarios y el crecimiento sostenido de la pequeña empresa del sector industrial de San Luis Potosí.

- Sí existe una relación directa entre la variable de Entrenamiento y la variable de Crecimiento en las empresas estudiadas.

- Existe una relación directa entre el nivel de capacitación de los empresarios y el personal que trabaja dentro de la pequeña empresa con el crecimiento sostenido de la misma.

- Sí existe una relación directa entre la variable de Entrenamiento y la variable de Crecimiento en las empresas estudiadas.

- Existe una relación directa entre el nivel de financiamiento que cuenta la empresa y el crecimiento sostenido de la pequeña empresa.

- No existe una relación directa entre la variable de Financiamiento y la variable de Crecimiento en las empresas estudiadas. Sin embargo, si el financiamiento es derivado de la utilización de reinversiones 
de las utilidades de años anteriores, sí existe una relación directa entre la variable de Financiamiento y la variable de Crecimiento en las empresas estudiadas.

- Los pequeños empresarios carecen de la información necesaria para poder llegar a tener un financiamiento para su empresa, el cual permita garantizar un crecimiento dentro de los primeros cinco años de vida.

- Los empresarios sí cuentan con la información necesaria para poder llegar a tener un financiamiento para su empresa; ellos catalogan que tener acceso a un préstamo es muy complicado y que los trámites para obtenerlo son muy difíciles de cumplir.

- ¿Los niveles de financiamiento, capacitación y entrenamiento son determinantes para que una pequeña empresa llegue a un crecimiento sostenido? Las variables determinantes para generar un crecimiento sostenido son la capacitación y el entrenamiento. El financiamiento no es de carácter determinante para lograr un crecimiento. 


\section{Referencias}

Arechavala, R. y Madriga, B. (2000). Métodos de estudios de la pequeña y mediana empresa: el argumento a favor de los estudios de casos. IV Congresos de investigación en México, 4(1), 47-66.

Arvanitis, R. (1996). Redes de investigación e innovación: un breve recorrido conceptual. Revista Latinoamericana de Estudios del Trabajo, 2(3), 41-54.

Comité de Planeación para el Desarrollo del Estado (2015). Programa Sectorial de Desarrollo Económico. Recuperado de http://www.slp.gob.mx/programas sectoriales2016-2021/assets/E1_2.pdf

Covey, S. R. (1997). Los siete hábitos de la gente altamente efectiva: la revolución ética en la vida cotidiana y en la empresa. Madrid: Planeta.

Crozier, M. y Friedberg, E. (1990). El actor y el sistema: las restricciones de la acción colectiva. Madrid: Alianza.

Danco, L. A. (1992). The real world of the entrepreneur. Agency Sales Magazine, 21(5), 60-62.

Diario Oficial de la Federación (2009). Acuerdo por el que se establece la estratificación de las micro, pequeñas y medianas empresas. Recuperado de http://dof.gob.mx/nota_detalle. php?codigo $=5096849 \&$ fecha $=30 / 06 / 2009$

Dotlich, D., \& Cairo, P. (2003). Why CEOs Fail. San Francisco: Jossey.
Dutrénit, G. y Vera-Cruz, A. (2002). Rompiendo paradigmas: acumulación de capacidades tecnológicas en la maquila de exportación. Innovación \& Competitividad, 2(6), 11-15.

Dyer, W. G. y Dyer, W. G. (1986). Organization development: System change or culture change? Personnel, 63(2), 14-18.

Estrada, M. R. (2015). Liderazgo: desarrollo de habilidades directivas. México: Manual Moderno.

Gélinier, O., \& Pagés, C. (1989). Estrategia y motivación. (s.c.): Civilización Ediciones.

Hernández, C. y Sánchez, M. (2004). Dinámica industrial e innovación en la industria productora de máquinas tortilladoras. En R. B. Rozo, Tecnología y finanzas en un marco de política económica sistémica. México: Universidad Autónoma Metropolitana, Unidad Xochimilco.

Hollander, B. S. y Elman, N. S. (1988). Familyowned businesses: An emerging field of inquiry. Family Business Review, 1(2), 145-164.

Inegi (Instituto Mexicano de Estadística y Geografía) (1999). Resumen de los resultados de los censos económicos. Recuperado de http://internet.contenidos. inegi.org.mx/contenidos/productos// prod_serv/contenidos/espanol/bvinegi/ productos/censos/economicos/1999/ general/resumen.pdf 
Inegi (Instituto Mexicano de Estadística y Geografía) (2004). Resumen general: censos económicos 2004. Recuperado de http://www.beta.inegi.org.mx/app/biblioteca/ficha.html?upc $=702825171193$

Inegi (Instituto Mexicano de Estadística y Geografía) (2008). Resumen de los resultados de los censos económicos 2008. Recuperado de http://www.inegi.org. $\mathrm{mx} /$ est/contenidos/espanol/proyectos/ censos/ce2009/pdf/RD09-resumen.pdf

Inegi (Instituto Mexicano de Estadística y Geografía) (2014). Censos económicos 2014: resultados definitivos. Recuperado de http://www.inegi.org.mx/est/contenidos/proyectos/ce/ce2014/

Martínez Rojas, M. A. (2012). Análisis de las PyMEs del sector industrial del estado de San Luis Potosí, bajo el enfoque de las competencias técnicas. Vértice Universitario, 14(56), 31-42.

National Research Council (2000). Surviving supply chain integration: Strategies for small manufacturers. Washington D. C.: National Academies Press.

Nonaka, I., Takeuchi, H. y Kocka, M. H. (1999). La organización creadora de conocimiento: cómo las compañías japonesas crean la dinámica de la innovación. México: Oxford University Press.

Raymond, J. L., Maroto, J. A. y Melle, M. (1999). Inversión y crecimiento empresarial: Factores condicionantes. Papeles de Economía Española, 78-79, 102-121.

Rubio, A. y Aragón, A. (2009). SMEs competitive behavior: Strategic resources and strategies. Management Research: Jour$\mathrm{nal}$ of the Iberoamerican Academy of Management, 7(3), 171-190.

Savall, H. (2003). An updated presentation of the socio-economic management model. Journal of Organizational Change Management, 16(1), 33-48.

Secretaría de Desarrollo Económico (2015). Las micro, pequeñas y medianas empresas en México y San Luis Potosí. Recuperado de http://www.sdeslp.gob.mx/estudios/ Las\%20MIPYMES\%20en $\% 20$ Mexico\%20 y\%20SLP.pdf

Serra, R., Iriarte, J. y Le Fosse, G. H. (2000). El nuevo juego de los negocios. Buenos Aires: Norma.

Thomsen, S., \& Pedersen, T. (2000). Ownership structure and economic performance in the largest European companies. 